\title{
A EFETIVAÇÃO DO PRINCÍPIO CONSTITUCIONAL DA PUBLICIDADE DOS ATOS ADMINISTRATIVOS COMO FORMA DE COIBIÇÃO DA CORRUPÇÃO PÚBLICA MEDIANTE O CONTROLE SOCIAL
}

\author{
Thiago Heitor da Fontoura Porto \\ Universidade de Santa Cruz do Sul - UNISC - Brasil \\ Caroline Cristiane Werle \\ Universidade de Santa Cruz do Sul - UNISC - Brasil
}

\section{Resumo}

A corrupção é uma patologia social que afeta diretamente o bem-estar da população, na medida em que os recursos que deveriam ser destinados aos serviços sociais são desviados para atender a interesses particulares. Ademais, a corrupção atinge a credibilidade das instituições públicas, colocando em risco o funcionamento salutar do Estado democrático. $\mathrm{O}$ presente artigo pretende, pois, avaliar, por meio do método dedutivo, se e de que modo a efetivação do princípio da publicidade, previsto no artigo 37 da Constituição Federal, pode servir como instrumento de prevenção e combate à corrupção pública no Brasil, considerando que a transparência dos atos administrativos é condição basilar para que seja possibilitado o seu controle social. Para tanto, utiliza-se da técnica de pesquisa bibliográfica e documental, notadamente mediante a pesquisa em livros, artigos científicos e, ainda, nos pertinentes instrumentos normativos nacionais e internacionais.

Palavras-chave: controle social, corrupção, publicidade, transparência.

\section{Introdução}

Foi em meio à construção dos estádios para a Copa do Mundo de 2014 que aparentemente a sociedade civil brasileira, de um modo geral, compreendeu que não poderia permanecer inerte na administração de um país autointitulado democrático. Mostrou-se necessária a consecução contrastante de obras faraônicas ao lado de famélicas favelas para que, enfim, ficassem evidenciados os grandes paradoxos existentes neste Estado.

E assim - utilizando-se de uma frase muito repetida nas manifestações de junho de 2013 -, "o gigante acordou”. De fato, por muitos anos, pode-se dizer que o povo brasileiro 
permaneceu adormecido diante de uma diuturna má gestão pública, protagonizada por agentes políticos que, em nada, representam os interesses dos cidadãos brasileiros. Pelo contrário, a conduta, em especial de chefes do executivo e membros do legislativo, tem se pautado na satisfação, primeiramente, de interesses próprios, secundariamente, em interesses partidários e, por fim, no interesse das empresas que os financiam.

Desse modo, faz-se mister a efetivação de mecanismos que permitam à sociedade brasileira exercer um controle direto da administração pública, o que, ademais, tenderia a diminuir os altos índices de impunidade verificáveis neste país. Destarte, o problema que se pretende responder neste artigo é o seguinte: de que modo se pode propiciar à sociedade civil um campo fértil para o exercício de uma cidadania ativa no combate à corrupção pública ${ }^{1}$ ?

A fim de responder ao problema proposto, primeiramente avalia-se qual a relação existente (ou inexistente) entre a corrupção e a natureza humana. Para tanto, é feita uma análise perfunctória das teorias de renomados filósofos, tais como Platão, Hobbes e Kant.

Dando-se prosseguimento à pesquisa bibliográfica, é feita uma avaliação da corrupção como fenômeno social, avaliando os deveres da sociedade cidadã no combate e na prevenção às patologias corruptivas. Nesse ponto, destacam-se as teorias de Rousseau, Starling, Gorczevski e Leal.

Na sequência, é feito um estudo dos principais instrumentos normativos internacionais que tratam da prevenção e combate à corrupção, especialmente no que tange à obrigatoriedade dos Estados Partes em promover a publicidade dos atos administrativos como forma de propiciar o controle social das patologias corruptivas. Nesse tópico, avaliam-se a Convenção de Mérida das Nações Unidas contra a Corrupção e a Convenção Interamericana Contra a Corrupção.

Continuando-se a investigação documental normativa, é feita uma análise de textos constitucionais, tanto da Constituição Federal vigente quanto da Estadual, avaliando-se os dispositivos que tratam da publicidade, da transparência e da participação social na Administração Pública.

Por fim, é feita uma avaliação da legislação infraconstitucional voltada para o combate à corrupção pela via do controle social, tópico em que se destacam a Lei de Responsabilidade Fiscal, a Lei da Transparência, a Lei de Acesso à Informação e a Lei de Improbidade

\footnotetext{
${ }^{1}$ Para os fins propostos neste artigo, será atribuído um conceito largo à expressão "corrupção pública", englobando as condutas previstas como atos de improbidade administrativa, os crimes dolosos que causem prejuízo à Administração Pública (notadamente os previstos no Título XI do Código Penal) e, enfim, qualquer ato ilícito intencional que venha a causar prejuízo ao erário ou mesmo à moralidade administrativa, vindo a corromper a saúde da gestão estatal.
}

Barbarói, Santa Cruz do Sul, Edição Especial n.44, p.<137-154>, jul./dez. 2015 
Administrativa.

\section{A corrupção e o ser humano}

Dê a um homem tudo o que ele deseja, e ele, apesar disso, naquele mesmo momento, sentirá que esse tudo não é tudo. (Imannuel Kant)

Preliminarmente, impende referir que a corrupção afigura-se como um "fenômeno de múltiplos fundamentos e nexos causais, tratada por diversos campos do conhecimento (filosofia, ciência, política, economia, sociologia, antropologia, ciência jurídica, etc.)" (LEAL, 2013, p. 80-81). Nesse capítulo, por sua vez, são enfocados especialmente os aspectos filosóficos e antropológicos do presente tema.

Insta mencionar que, embora hodiernamente sejam mais divulgados nos meios de comunicação os casos de corrupção pública, não se pode afirmar ser esse fenômeno patológico uma exclusividade de nossa época. Pelo contrário, a corrupção acompanha o homem desde o início da civilização, de modo que, inclusive, tem sido considerada por renomados filósofos como resultado de uma má natureza própria do ser humano.

Nesse sentido, impende destacar que Immanuel Kant, conforme colacionado em epígrafe, já alertava para um dos vícios humanos que mais estimulam a corrupção, qual seja: a ganância ${ }^{2}$. Para o homem, “o melhor dos bens é o que não se possui”" (ASSIS, 1998, p. 7). Com efeito, essa insaciedade afigura-se mais insuportável "do que a extrema pobreza. Pois maior o apetite, maior se torna a necessidade" (DEMÓCRITO, 1998, p. 118). Na mesma senda, Platão apud Giannetti (2008, p. 281) aduz que "a pobreza resulta do aumento dos desejos do homem, não da diminuição de sua propriedade".

Thomas Hobbes (2006) é outro que dessumiu da natureza do homem a falibilidade egoística que faz com que pautemos nossa conduta exclusivamente visando aos nossos próprios interesses, ainda que, para tanto, seja necessário agir em prejuízo de interesses alheios $^{3}$ - afinal, o homem é o lobo do homem. Para Hobbes, o interesse insaciável do homem é o poder, que "consiste nos meios de que presentemente dispõe para obter qualquer visível

\footnotetext{
${ }^{2}$ Muito antes disso, Sólon, no século VI A.C., também chamava atenção para a ausência de limites para a ganância humana, porquanto "aqueles que hoje dispõem das maiores fortunas entre nós possuem também o dobro da voracidade dos demais" (SÓLON apud GIANNETTI, 2008, p. 245).

${ }^{3}$ Lapidar nesse sentido o escólio de Calil Simão (2011, p. 34), segundo o qual a corrupção "é caracterizada pela incapacidade moral dos cidadãos de assumir compromissos voltados ao bem comum. Vale dizer, os cidadãos mostram-se incapazes de fazer coisas que não lhes tragam uma gratificação pessoal".
} 
bem futuro" (2006, p. 70).

Com efeito, o renomado filósofo inglês considera que o que efetivamente move o ser humano - além do medo da morte - é o seu desejo pelo poder, o qual pode estar representado, por exemplo, pela riqueza, pelo saber e pela honra, que, segundo o autor (2006), não são nada além de formas diferentes de poder.

Embora se reconheça, tal como referido supra, que a honra e a sabedoria já tenham, de fato, sido objeto maior de desejo humano em outras épocas, a verdade é que, desde que o dinheiro surgiu, em meados do século VII A.C., o homem tem tido com ele uma relação que beira o fetichismo. Atualmente, em uma sociedade em que tudo é negociável, o dinheiro figura como a principal e mais incisiva fonte de poder. Além disso, observa-se que as pessoas que mais inspiram respeito nos demais são as que possuem uma maior capacidade econômica.

Heráclito já avisava que as virtudes mais transcendentes são pouco festejadas pelas pessoas em geral, ficando restritas ao apreço de uma minoria. "Uma coisa preferem os melhores homens em relação a tudo o mais: a glória eterna aos bens mortais, mas a maioria se empaturra como o gado" (HERÁCLITO, 1998, p. 38). Nesse mesmo sentido, Arthur Shopenhauer citando Francis Bacon diagnosticou que "as virtudes inferiores recebem o aplauso das pessoas comuns; as intermediárias, admiração, e as mais elevadas nenhuma apreciação" (SHOPENHAUER apud GIANNETTI, 2008, p. 62).

A verdade é que está arraigado em nossa cultura valorizar a riqueza material (virtude inferior) acima de quaisquer outras virtudes. Verifica-se que a valorização do capital supera a da sabedoria (tida por Sócrates como a maior das virtudes) e mesmo a da honra e da honestidade (virtudes que, se fossem devidamente prestigiadas, teriam força de até mesmo extirpar a corrupção). Para a maioria das pessoas, quem é sábio, honesto, íntegro, sem ter dinheiro, é, na realidade, tolo ${ }^{4}$.

Percebe-se que a virtude inferior consubstanciada na riqueza material recebe ovação social, sendo, destarte, intensamente desejada pelos homens. E como já alertava Demócrito (1998, p. 110), “desejar violentamente uma coisa é tornar-se cego para o demais".

\footnotetext{
${ }^{4}$ Tal situação é muito bem demonstrada no episódio "Doug's in the money" da série "Doug Funnie", popular nos anos 90. No episódio, o personagem Doug encontra na calçada uma considerável quantia em dinheiro e, a partir disso, vive o dilema de apropriar-se dele ou leva-lo à polícia. Embora estivesse financeiramente pobre (broke), Doug resolve entregá-lo à polícia, sendo alvo de piadas dos demais personagens. No entanto, passam-se mais de 30 dias sem ninguém ter reclamado a perda do dinheiro e, assim, conforme a legislação local, o valor é devolvido a Doug. Imediatamente, o sofrido personagem passou a ser muito bajulado e respeitado por todos. Mas mais uma reviravolta ainda estava por vir: Doug descobre por acaso que o dinheiro pertencia a uma senhora idosa e, mesmo sendo legalmente dono daqueles vultuosos valores, resolve seguir sua consciência e entrega o dinheiro para sua proprietária original. Mais uma vez, acabou sendo alvo de chacotas, tendo entretanto saído satisfeito consigo mesmo. O mencionado episódio pode ser visto no link a seguir colacionado: $<$ www.youtube.com/watch?v=6IJIFnhBqnY>.
} 
Com efeito, o corrupto, ao se inebriar com o desejo do poder pecuniário, perde a capacidade de se sensibilizar com os malefícios que sua conduta insidiosa está a causar para toda uma coletividade, seja pelo sucateamento de escolas, de hospitais e das políticas públicas em geral, seja por eivar a confiança e a moralidade de uma sociedade.

Diante disso, verifica-se que o texto bíblico contido no livro 1 Timóteo capítulo 6, versículo 10 afigura-se inabalavelmente atual: "o amor ao dinheiro é a raiz de todos os males”. Ainda mais antigo, porém igualmente amoldado aos tempos modernos, Sófocles, mediante seu personagem Creonte, assevera com autoridade que "nenhuma instituição pior que o dinheiro floresceu entre os homens. Cidades devasta, [...] alicia e seduz corações virtuosos a praticar ações infames. Leva homens a cometer crimes e os inicia na impiedade, origem de todo mal" (SÓFOCLES, 1999, p. 14-15).

De fato, quase sempre motivada pela avareza, a corrupção afigura-se como uma ação abominável e imoral cujas consequências pulverizadas (e, por isso mesmo, veladas) podem ensejar até mesmo a morte de inocentes pela falta de investimento em segurança pública, leitos hospitalares, medicamentos, etc.

Com essa reflexão e cientes de que o homem, por natureza, é um animal político (conforme já diagnostigado por Aristóteles), parte-se para o próximo capítulo em que se analisará a corrupção como fenômeno social e sua relação com o conceito de cidadania.

\section{A corrupção e a sociedade cidadã}

Naquela época, os homens muitas vezes ingeriam veneno por ignorância; hoje em dia, mais bem instruídos, eles envenenam uns aos outros (Lucrécio)

Rousseau (2006), em completa contraposição às teorias hobbesianas, considera que os comportamentos viciosos da ganância, avareza e egoísmo não são fruto de uma suposta má natureza humana, mas sim seriam propriamente resultados da vida em sociedade, a qual incita a desigualdade e o jugo dos mais fortes sobre os mais fracos. Na visão romântica do "bom selvagem", Rousseau entende ser o homem bom por natureza, de modo que é a sociedade que o corrompe.

Em se tratando de "corrupção", a origem etimológica da palavra não desmente as teorias de Rousseau. Afinal, as patologias corruptivas se tratam de condutas que não podem ser efetuadas de modo solitário/isolado, afigurando-se como típicos fenômenos sociais.

Com efeito, a palavra "corrupção" deriva do latim "corrumpere” que, por sua vez, é 
resultado da justaposição do prefixo "co" com o verbo "rumpere”. Esta última parte da palavra denota "ruptura", "violação", "deterioração", "transgressão", enquanto que o prefixo "co" significa que essa ruptura é realizada por mais de um, isto é, dá-se mediante um vínculo entre duas ou mais pessoas.

Atento à sua origem etimológica, Starling (2008, p. 259) aduz que "a palavra corrupção aponta para dois movimentos: algo que se quebra em um vínculo; algo que se degrada no momento dessa ruptura". As consequências disso no âmbito social são desastrosas, visto que "de um lado, quebra-se o princípio da confiança, o elo que permite o cidadão associar-se para intervir na vida de seu país. De outro, degrada-se o sentido do público" (STARLING, 2008, p. 259).

Nesse diapasão, o fenômeno patológico sob estudo, no escólio de Gorczevski (2014, p. 71), propicia um quadro favorável ao surgimento de "um governo despótico que tentará perpetuar-se mediante a sistemática destruição da virtude cívica”. No mesmo sentido, Starling (2008, p. 259) preconiza que, para um regime ditatorial, "a corrupção tem funcionalidade: serve para garantir a dissipação da vida pública".

Com efeito, é possível observar que isso se afigura como uma realidade concreta em muitos Estados, “cujos habitantes aceitam silenciosamente práticas ilícitas por parte de um governo de homens que, sigilosa e astutamente, vão afastando o governo das leis" (GORCZEVSKI, 2014, p. 71). Sinale-se não haver democracia que resista ilesa às patologias corruptivas, visto que os nefastos efeitos desse fenômeno social tem aptidão para "dissolver os princípios políticos que sustentam as condições para o exercício da virtude do cidadão" (STARLING, 2008, p. 259).

Mas, afinal, o que constitui ontologicamente um cidadão? Há de se reconhecer que "não há um conceito rígido de cidadania, pois não se trata de algo estático" (GORCZEVSKI e MARTIN, 2011, p. 27). Contudo, conforme preconiza Loureiro (2009. p. 175) pode-se dizer sucintamente que "cidadania é o direito a ter direitos, além do dever de lutar por estes". De forma complementar, pode-se dizer, ainda, que "cidadão é aquele que tem o poder de tomar parte na administração deliberativa ou judicial da cidade" (GORCZEVSKI, 2012, p. 36).

Sob esse prisma, constata-se que ser cidadão não pressupõe ser um ente passivo ${ }^{5}$ na administração do Estado. Pelo contrário, faz parte do conceito de cidadania ter voz ativa na

\footnotetext{
${ }^{5}$ Convém mencionar que, dentre as causas da passividade dos cidadãos não se encontram apenas um suposto temor a governos tirânicos. Pelo contrário, no âmbito de governos neoliberais altamente assistencialistas, tais como o próprio Brasil, verifica-se que a sociedade, historicamente habituada a receber "gratuitamente" diversos direitos sociais, permanece acomodada, isto é, inerte na administração de seu país (LEAL, 2008); panorama semelhante ao "pão e circo" da Roma antiga.
}

Barbarói, Santa Cruz do Sul, Edição Especial n.44, p.<137-154>, jul./dez. 2015 
gestão estatal (LEAL, 2013, p. 204-217). Isso, porque a

\begin{abstract}
omissão e passividade [dos cidadãos] indubitavelmente abre caminho para que homens sem alma se apropriem das coisas públicas, para a execução de políticas públicas equivocadas, para as tributações injustas, os direitos sociais sonegados, os privilégios de grupos, as desigualdades e injustiças sociais, a inoperância dos governos. (GORCZEVSKI, 2014, p. 78) ${ }^{6}$.
\end{abstract}

Dessa forma, cumpre que o Estado propicie condições favoráveis para a participação da sociedade cidadã na sua gestão, em especial no tocante ao controle da corrupção. Para tanto, não há método mais basilar do que garantir que os atos estatais se darão de forma transparente. Com efeito, confia-se que "it is the surest way of guarding against corruption, and helps increase trust in the people and institutions on which our futures depend" (TRANSPARENCY INTERNATIONAL, www.transparency.org).

Assim, no próximo capítulo, avaliam-se os instrumentos normativos internacionais que determinam aos Estados Partes (incluindo o Brasil) a obrigação de agir em conformidade com o princípio da publicidade dos atos administrativos.

\title{
4. A previsão em instrumentos normativos internacionais do princípio da publicidade como coibição à corrupção pública
}

O acesso à informação em poder do Estado é um direito fundamental do indivíduo.

$\left(O E A^{8}\right)$

A corrupção tem recebido a atenção de organismos internacionais, por meio dos quais diversos países passaram a conjugar esforços no combate às patologias corruptivas. Pode-se dizer que, nos tempos de intensa globalização em que vivemos, isso é algo, de fato, absolutamente imprescindível se o objetivo é levar a sério o intento de erradicar ou, ao menos, minimizar esse corrosivo fenômeno social. Como bem diagnosticado pela Organização das

\footnotetext{
${ }^{6}$ De forma complementar, cumpre referir que "para quem governa sem a ética intenção de fazer o bem coletivo, mas apenas de defender meros interesses privados, a omissão popular é providencial, já que, quando não há cobranças ou participação/fiscalização, os administradores atuam ao seu bel-prazer, [...]. [Isso] enfraquece a democracia e fortalece o surgimento das patologias corruptivas (GORCZEVSKI, 2014, p. 78).

${ }^{7}$ Tradução livre: "Essa é a maneira mais segura de se proteger contra a corrupção e de se aumentar a confiança nas pessoas e nas instituições de que nosso futuro depende".

${ }^{8}$ item 4 da Declaração de Princípios Sobre Liberdade de Expressão da Organização dos Estados Americanos que, em seu teor completo, possui o seguinte comando: "O acesso à informação em poder do Estado é um direito fundamental do indivíduo. Os Estados estão obrigados a garantir o exercício desse direito. Este princípio só admite limitações excepcionais que devem estar previamente estabelecidas em lei para o caso de existência de perigo real e iminente que ameace a segurança nacional em sociedades democráticas". Disponível em $<$ http://www.cidh.oas.org $>$.
}

Barbarói, Santa Cruz do Sul, Edição Especial n.44, p.<137-154>, jul./dez. 2015 
Nações Unidas (ONU) " "a corrupção deixou de ser um problema local para converter-se em um fenômeno transnacional que afeta todas as sociedades e economias, [assim] faz-se necessária a cooperação internacional para preveni-la e lutar contra ela" (ONU, 2003, www.planalto.gov.br) (sem grifos no original). Desse modo, neste capítulo avaliam-se os instrumentos normativos internacionais pertinentes ao tema sub examine, notadamente aqueles de que o Brasil seja signatário. Destarte, releva trazer à baila, primeiramente, a Convenção Interamericana contra a Corrupção, promulgada no Brasil pelo Decreto n 4.410, de 7 de outubro de 2002.

O aludido pacto internacional, firmado no âmbito da Organização dos Estados Americanos, foi criado, dentre outras razões, ante o fato de que "a corrupção solapa a legitimidade das instituições públicas e atenta contra a sociedade, a ordem moral e a justiça, bem como contra o desenvolvimento integral dos povos" (OEA, 1996, www.planalto.gov.br). Outra motivação prevista no preâmbulo da Convenção Interamericana que merece destaque é a que reconhece a "necessidade de reforçar a participação da sociedade civil na prevenção e na luta contra a corrupção" (OEA, 1996, www.planalto.gov.br) (sem grifos no original).

Diante disso, verifica-se que, desde seu texto preambular, a OEA deixou evidenciada a relevância por ela atribuída ao controle social das patologias corruptivas. À guisa de corroboração do expendido, o artigo III da Convenção em comento - concernente às medidas preventivas - determina aos Estados Partes que apliquem, em seu âmbito interno, medidas "destinadas a manter e fortalecer [...] mecanismos para estimular a participação da sociedade civil e de organizações não-governamentais nos esforços para prevenir a corrupção" (OEA, 1996, www.planalto.gov.br) (sem grifos no original). No mesmo artigo, determina, ainda, a implementação de "sistemas de recrutamento de funcionários públicos e de aquisição de bens e serviços por parte do Estado de forma a assegurar sua transparência, eqüidade e eficiência" (OEA, 1996, www.planalto.gov.br) (sem grifos no original).

Outro dispositivo que convém trazer à colação é o artigo XIV da vertente Convenção, o qual está inserido no capítulo referente à assistência e cooperação. Veja-se a seguir o seu teor:

os Estados Partes prestarão [...] a mais ampla cooperação técnica recíproca sobre as formas e métodos mais efetivos para prevenir, detectar, investigar e punir os atos de corrupção. Com esta finalidade, facilitarão o intercâmbio de experiências por meio de acordos e reuniões entre os órgãos e instituições competentes e dispensarão

\footnotetext{
9 De modo semelhante a Organização dos Estados Americanos concluiu que a corrupção "se reveste de transcendência internacional, o que exige por parte dos Estados uma ação coordenada para combatê-la eficazmente". (OEA, 1996, www.planalto.gov.br).
} 
atenção especial às formas e métodos de participação civil na luta contra a $\underline{\text { corrupção }}$ (OEA, 1996, www.planalto.gov.br). (sem grifos no original)

Assim, uma vez demonstrada a preocupação em nível continental quanto ao combate à corrupção pela via do controle social, pode-se agora voltar as atenções para um instrumento normativo internacional de escala global, qual seja: a Convenção das Nações Unidas contra a Corrupção, ratificada pelo Brasil no dia 15 de junho de 2005 e promulgada pelo Decreto $\mathrm{n}^{\circ}$ 5.687/2006. O referido pacto foi criado - dentre outras motivações enumeradas em seu preâmbulo - ante as “ameaças decorrentes da corrupção, para a estabilidade e a segurança das sociedades, ao enfraquecer as instituições e os valores da democracia, da ética e da justiça e ao comprometer o desenvolvimento sustentável e o Estado de Direito" (ONU, 2003, www.planalto.gov.br).

Outra razão elencada pelas Nações Unidas que merece destaque é a seguinte:

a prevenção e a erradicação da corrupção são responsabilidades de todos os Estados e [...] estes devem cooperar entre si, com o apoio e a participação de pessoas $e$ grupos que não pertencem ao setor público, como a sociedade civil, as organizações não-governamentais e as organizações de base comunitárias, para que seus esforços neste âmbito sejam eficazes. (ONU, 2003, www.planalto.gov.br) (sem grifos no original)

Observa-se, destarte, que, do mesmo modo como ocorrera na Convenção Interamericana, a ONU, desde o preâmbulo da Convenção das Nações Unidas, revelou inexoravelmente a importância que atribui ao controle social como mecanismo de combate e prevenção à corrupção. Nesse mesmo diapasão, faz-se mister enaltecer o disposto no artigo 5, item 1 (concernente ao capítulo "políticas e práticas de prevenção da corrupção") da Convenção sob estudo, segundo o qual, todos os Estados Partes deverão formular, aplicar ou manter em vigor

políticas coordenadas e eficazes contra a corrupção que promovam a participação da sociedade e reflitam os princípios do Estado de Direito, a devida gestão dos assuntos e bens públicos, a integridade, a transparência e a obrigação de render contas. (ONU, 2003, www.planalto.gov.br) (sem grifos no original)

Ademais, igualmente releva trazer à colação o disposto no artigo 10 (referente ao capítulo "informação pública") da Convenção em comento, de acordo com o qual, haja vista

a necessidade de combater a corrupção, cada Estado Parte, em conformidade com os princípios fundamentais de sua legislação interna, adotará medidas que sejam necessárias para aumentar a transparência em sua administração pública, inclusive no relativo a sua organização, funcionamento e processos de adoção de decisões, quando proceder. Essas medidas poderão incluir, entre outras coisas: a) A instauração de procedimentos ou regulamentações que permitam ao público em geral obter, quando proceder, informação sobre a organização, o funcionamento e os 
processos de adoção de decisões de sua administração pública[...] b) A simplificação dos procedimentos administrativos, quando proceder, a fim de facilitar o acesso do público às autoridades encarregadas da adoção de decisões; e c) A publicação de informação, o que poderá incluir informes periódicos sobre os riscos de corrupção na administração pública. (ONU, 2003, www.planalto.gov.br) (sem grifos no original)

Ainda, insta mencionar o teor de seu artigo 13, item 1, que também trata da participação da sociedade civil na prevenção e combate à corrupção. Senão, vejamos o que diz o referido dispositivo:

cada Estado Parte adotará medidas adequadas, [...] de conformidade com os princípios fundamentais de sua legislação interna, para fomentar a participação ativa de pessoas e grupos que não pertençam ao setor público, como a sociedade civil, as organizações não-governamentais e as organizações com base na comunidade, na prevenção e na luta contra a corrupção, e para sensibilizar a opinião pública a respeito à existência, às causas e à gravidade da corrupção, assim como a ameaça que esta representa. Essa participação deveria esforçar-se com medidas como as seguintes: a) Aumentar a transparência e promover a contribuição da cidadania aos processos de adoção de decisões; b) Garantir o acesso eficaz do público à informação; c) Realizar atividade de informação pública para fomentar a intransigência à corrupção, assim como programas de educação pública, incluídos programas escolares e universitários; d) Respeitar, promover e proteger a liberdade de buscar, receber, publicar e difundir informação relativa à corrupção [...]. (ONU, 2003, www.planalto.gov.br) (sem grifos no original)

Por fim, complementarmente o item 2 do mesmo artigo determina que Cada Estado Parte deverá adotar

medidas apropriadas para garantir que o público tenha conhecimento dos órgãos pertinentes de luta contra a corrupção mencionados na presente Convenção, e facilitará o acesso a tais órgãos, quando proceder, para a denúncia, inclusive anônima, de quaisquer incidentes que possam ser considerados constitutivos de um delito qualificado de acordo com a presente Convenção. (ONU, 2003, www.planalto.gov.br) (sem grifos no original)

Pelos dispositivos colacionados acima, resta demonstrada a convicção das Nações Unidas, no sentido de o controle social ser imprescindível para a prevenção e o combate efetivo à corrupção, o que só será possível caso o Estado atue de modo transparente.

Dessa forma, a pesquisa levada a efeito neste capítulo confirma que, tanto em nível continental quanto em nível global, existem determinações para que os Estados Partes (incluindo o Brasil) implementem medidas capazes de assegurar a participação da sociedade no controle da corrupção, destacando-se a importância atribuída à publicidade dos atos administrativos.

Nos próximos capítulos, volvem-se as atenções para o Direito interno brasileiro, a 
começar pelas previsões pertinentes dispostas na Constituição Federal e Estadual (do Rio Grande do Sul).

\section{Publicidade e transparência dos atos administrativos: exigências da Constituição Federal e da Constituição Estadual}

Todo poder emana do povo. (Constituição Federal)

No momento atual, em que o Direito passa a ser interpretado em um viés póspositivista, as Constituições adquirem um papel de grande relevância, dando coesão aos ordenamentos jurídicos, o que fazem notadamente por meio de seus princípios. Com efeito, releva salientar que o princípio da publicidade administrativa encontra-se previsto expressamente em nossa Constituição, mais precisamente no artigo 37, de acordo com o qual “a administração pública direta e indireta de qualquer dos Poderes da União, dos Estados, do Distrito Federal e dos Municípios obedecerá aos princípios de legalidade, impessoalidade, moralidade, publicidade e eficiência" (BRASIL, 1988, www.planalto.gov.br).

Evidentemente que todos os princípios elencados no artigo supracitado, desde que observados no cotidiano da administração pública, têm força de extirpar ou, pelo menos, minimizar a incidência das patologias corruptivas. Afinal, a corrupção é - ao mesmo tempo ilegal, imoral, engendrada para a satisfação de interesses pessoais, exercida de forma velada (não pública) e invariavelmente tem como resultado a ineficiência dos atos administrativos.

Todavia, o presente artigo tem como escopo analisar mais detidamente apenas o princípio da publicidade administrativa, uma vez que se confia ser este o mandamento de otimização que, se observado, tem força de propiciar um campo fértil para o controle social. Assim, no escólio de Marçal Filho (2005, p. 14-15), o princípio da publicidade significa que

\footnotetext{
o exercício do poder deve ser acessível ao conhecimento de toda a comunidade e, especialmente, daqueles que serão afetados pelo ato decisório. A publicidade se afirma como instrumento de transparência e verificação da lisura dos atos praticados
}

De outra parte, figurando como um desdobramento do princípio da publicidade, a transparência possui previsão implícita na Constituição Federal. O aludido princípio, consoante já visto nos pactos internacionais, exige do Estado não apenas a divulgação dos atos governamentais, mas sim que o conteúdo divulgado seja passível de compreensão por parte dos cidadãos, "ou seja, a sociedade deve conhecer e entender o que está sendo 
divulgado" (GUERRA, 2003, p. 91).

Nesse passo, cumpre avaliar os dispositivos constitucionais que revelam a importância atribuída pelo legislador constituinte a esses dois princípios. Primeiramente, impende destacar que o princípio da publicidade e transparência estão espraiados por toda a ordem jurídica nacional (LEAL, 2009, p. 13), sendo elevados, inclusive, à condição de direitos fundamentais. Com efeito, prevê o artigo $5^{\circ}$ da Constituição, em seu inciso XIV que "é assegurado a todos o acesso à informação [...]” (BRASIL, 1988, www.planalto.gov.br). Ademais, o inciso XXXIII do mesmo artigo aduz que

\footnotetext{
todos têm direito a receber dos órgãos públicos informações de seu interesse particular, ou de interesse coletivo ou geral, que serão prestadas no prazo da lei, sob pena de responsabilidade, ressalvadas aquelas cujo sigilo seja imprescindível à segurança da sociedade e do Estado (BRASIL, 1988, www.planalto.gov.br).
}

Ainda dentre os direitos fundamentais previstos no art. $5^{\circ}$ da Lei Maior, figura, no inciso LXXII, o remédio constitucional habeas data, instrumento judicial existente, dentre outras razões, "para assegurar o conhecimento de informações relativas à pessoa do impetrante, constantes de registros ou bancos de dados de entidades governamentais ou de caráter público" (BRASIL, 1988, www.planalto.gov.br).

Outrossim, dentre os dispositivos constitucionais que contemplam os princípios da publicidade e da transparência, ainda cabe citar o artigo $37, \S 3^{\circ}$, inciso II, o qual determina que a "a lei disciplinará as formas de participação do usuário na administração pública direta e indireta, regulando especialmente [...] o acesso dos usuários a registros administrativos e a informações sobre atos de governo" (BRASIL, 1988, www.planalto.gov.br) (sem grifos no original).

Por fim, cumpre destacar o comando inserto no artigo 216, $\S 2^{\circ}$ da Constituição Federal, segundo o qual “cabem à administração pública, na forma da lei, a gestão da documentação governamental e as providências para franquear sua consulta a quantos dela necessitem" (BRASIL, 1988, www.planalto.gov.br) (sem grifos no original).

Desse modo, passa-se a avaliar a Constituição Estadual do Rio Grande do Sul, cujo grande mérito foi ter previsto expressamente como princípio da administração pública, além do princípio da publicidade, o princípio da participação popular. Senão, vejamos:

Art. 19. A administração pública direta e indireta de qualquer dos Poderes do Estado e dos municípios, visando à promoção do bem público e à prestação de serviços à comunidade e aos indivíduos que a compõe, observará os princípios da legalidade, da moralidade, da impessoalidade, da publicidade, da legitimidade, da participação, 
da razoabilidade, da economicidade, da motivação (RIO GRANDE DO SUL, 1989, www2.al.rs.gov.br) (sem grifos no original)

Ante o exposto, resta demonstrada a convergência das Constituições analisadas com o direito internacional, no sentido de que ambas valorizam sobremaneira os princípios da publicidade e transparência, com vistas a permitir a participação social no controle dos atos administrativos.

No próximo capítulo, avalia-se a legislação infraconstitucional pertinente ao tema em estudo.

\section{A publicidade e a transparência na legislação nacional}

A responsabilidade na gestão fiscal pressupõe a ação planejada e transparente, em que se previnem riscos e corrigem desvios capazes de afetar o equilíbrio das contas públicas. (LC $\left.n^{\circ} 101 / 2000\right)$

A partir do ano de 2009, com a entrada em vigor da chamada Lei da Transparência (Lei Complementar $n^{\circ} 131$ ), verificaram-se grandes avanços em matéria de efetivação do princípio constitucional da publicidade dos atos administrativos. Com efeito, o referido diploma legal

alterou a redação da Lei de Responsabilidade Fiscal no que se refere à transparência da gestão fiscal, inovando ao determinar a disponibilização, em tempo real ${ }^{10}$, de informações pormenorizadas sobre a execução orçamentária e financeira da União, dos Estados, do Distrito Federal e dos Municípios. (BRASIL, www.portaldatransparencia.gov.br)

A referida Lei Complementar, dentre outras alterações, modificou o conteúdo do parágrafo único do artigo 48 da Lei de Responsabilidade Civil (Lei Complementar $n^{\circ}$ 101, de 2000), o qual estabelece, em seu caput, alguns dos instrumentos de transparência da gestão fiscal ${ }^{11}$. Desse modo, cumpre trazer à baila a alteração efetuada pela Lei da Transparência, a qual elencou mecanismos concretos de efetivação do princípio da publicidade, quais sejam:

\footnotetext{
${ }^{10}$ Convém referir que, "conforme definido pelo Decreto $\mathrm{n}^{\circ} 7.185 / 2010$, a liberação em tempo real se refere à disponibilização das informações, em meio eletrônico que possibilite amplo acesso público, até o primeiro dia útil subseqüente à data do registro contábil no respectivo sistema, sem prejuízo do desempenho e da preservação das rotinas de segurança operacional necessários ao seu pleno funcionamento" (BRASIL, www.portaldatransparencia.gov.br).

11 "Art. 48. São instrumentos de transparência da gestão fiscal, aos quais será dada ampla divulgação, inclusive em meios eletrônicos de acesso público: os planos, orçamentos e leis de diretrizes orçamentárias; as prestações de contas e o respectivo parecer prévio; o Relatório Resumido da Execução Orçamentária e o Relatório de Gestão Fiscal; e as versões simplificadas desses documentos" (BRASIL, 2000, www.planalto.gov.br).
} 
I - incentivo à participação popular e realização de audiências públicas, durante os processos de elaboração e discussão dos planos, lei de diretrizes orçamentárias e orçamentos;

II - liberação ao pleno conhecimento e acompanhamento da sociedade, em tempo real, de informações pormenorizadas sobre a execução orçamentária e financeira, em meios eletrônicos de acesso público ${ }^{12}$;

III - adoção de sistema integrado de administração financeira e controle, que atenda a padrão mínimo de qualidade estabelecido pelo Poder Executivo da União e ao disposto no art. 48-A. (BRASIL, 2009, www.planalto.gov.br)

Outrossim, é de todo oportuno trazer à lume o artigo 73-A (BRASIL, 2009, www.planalto.gov.br), dispositivo incluído pela lei em comento, cujo teor define que qualquer cidadão, partido político, associação ou sindicato afigura-se como "parte legítima para denunciar ao respectivo Tribunal de Contas e ao órgão competente do Ministério Público o descumprimento das prescrições estabelecidas" na Lei de Responsabilidade Fiscal. Desse modo, restam ilustrados relevantes dispositivos da Lei Complementar $n^{\circ} 101$, com as alterações efetuadas pela Lei da Transparência.

Nesse passo, cumpre analisar dispositivos de outro diploma legal, em que se pode verificar, de modo hialino, a intenção do legislador brasileiro em dar efetividade ao princípio da publicidade dos atos administrativos. Trata-se da Lei de Acesso à Informação (Lei $n^{\circ} 12.527$, de 18 de novembro de 2011), a qual, em seu artigo $8^{\circ}$ determina aos órgãos e entidades públicas a obrigação de "promover, independentemente de requerimentos, a divulgação em local de fácil acesso, no âmbito de suas competências, de informações ${ }^{13}$ de interesse coletivo ou geral por eles produzidas ou custodiadas" (BRASIL, 2011, www.planalto.gov.br), utilizando-se de "todos os meios e instrumentos legítimos de que dispuserem, [inclusive] sendo obrigatória a divulgação em sítios ${ }^{14}$ oficiais da rede mundial de

\footnotetext{
12 Elucidando o modus como isso deve ocorrer, o art. 48-A, o qual também fora introduzido pela Lei da Transparência, determina que os entes da Federação deverão disponibilizar "a qualquer pessoa física ou jurídica o acesso a informações referentes a: I - quanto à despesa: todos os atos praticados pelas unidades gestoras no decorrer da execução da despesa, no momento de sua realização, com a disponibilização mínima dos dados referentes ao número do correspondente processo, ao bem fornecido ou ao serviço prestado, à pessoa física ou jurídica beneficiária do pagamento e, quando for o caso, ao procedimento licitatório realizado; II - quanto à receita: o lançamento e o recebimento de toda a receita das unidades gestoras, inclusive referente a recursos extraordinários. (BRASIL, 2009, www.planalto.gov.br)

${ }^{13} \mathrm{De}$ acordo com o $\S 1^{\circ}$ do vertente dispositivo legal, tais informações devem conter, "no mínimo: I - registro das competências e estrutura organizacional, endereços e telefones das respectivas unidades e horários de atendimento ao público; II - registros de quaisquer repasses ou transferências de recursos financeiros; III registros das despesas; IV - informações concernentes a procedimentos licitatórios, inclusive os respectivos editais e resultados, bem como a todos os contratos celebrados; V - dados gerais para o acompanhamento de programas, ações, projetos e obras de órgãos e entidades; e VI - respostas a perguntas mais frequentes da sociedade (BRASIL, 2011, www.planalto.gov.br).

${ }^{14}$ De acordo com o $\$ 3^{\circ}$ do artigo em análise, tais sítios devem "atender, entre outros, aos seguintes requisitos: I conter ferramenta de pesquisa de conteúdo que permita o acesso à informação de forma objetiva, transparente, clara e em linguagem de fácil compreensão; II - possibilitar a gravação de relatórios em diversos formatos eletrônicos, inclusive abertos e não proprietários, tais como planilhas e texto, de modo a facilitar a análise das informações; III - possibilitar o acesso automatizado por sistemas externos em formatos abertos, estruturados e
}

Barbarói, Santa Cruz do Sul, Edição Especial n.44, p.<137-154>, jul./dez. 2015 
computadores (internet)" (BRASIL, 2011, www.planalto.gov.br).

Por fim, ainda releva salientar que, de acordo com o artigo 11, inciso IV da Lei $\mathrm{n}^{\mathrm{o}}$ 8.429/92, "constitui ato de improbidade administrativa que atenta contra os princípios da administração pública [...] negar publicidade aos atos oficiais" (BRASIL, 1992, www.planalto.gov.br) (sem grifos no original). Com efeito, ex vi do disposto no artigo 12, inciso III da lei em tela, aquele que incorrer na conduta descrita acima, além de sofrer as sanções penais, civis e administrativas porventura aplicáveis, estará

\begin{abstract}
sujeito às seguintes cominações, que podem ser aplicadas isolada ou cumulativamente, de acordo com a gravidade do fato: [...] ressarcimento integral do dano, se houver, perda da função pública, suspensão dos direitos políticos de três a cinco anos, pagamento de multa civil de até cem vezes o valor da remuneração percebida pelo agente e proibição de contratar com o Poder Público ou receber benefícios ou incentivos fiscais ou creditícios, direta ou indiretamente, ainda que por intermédio de pessoa jurídica da qual seja sócio majoritário, pelo prazo de três anos (BRASIL, 1992, www.planalto.gov.br).
\end{abstract}

Desse modo, resta demonstrado o esmero do legislador nacional a fim de dar efetividade ao princípio da publicidade e, bem assim, propiciar um campo fértil para o controle social da corrupção.

\title{
7. Considerações finais
}

A república democrática - res pública não apenas no sentido próprio da palavra, mas também no sentido de exposta ao público - exige que o poder seja visível (Norberto Bobbio)

É inegável que a corrupção está ligada a alguns vícios naturais do ser humano, tais como a ganância e o egoísmo (características comuns em corruptos e corruptores). Também se afigura evidente que o modelo social capitalista, ao invés de reprimir certos impulsos naturais do homem, incentiva-os, formando seres avarentos, consumistas e, bem assim, extremamente propícios a incidir em patologias corruptivas.

Contudo, os funestos efeitos da corrupção não permitem ao Estado utilizar-se do

legíveis por máquina; IV - divulgar em detalhes os formatos utilizados para estruturação da informação; V garantir a autenticidade e a integridade das informações disponíveis para acesso; VI - manter atualizadas as informações disponíveis para acesso; VII - indicar local e instruções que permitam ao interessado comunicar-se, por via eletrônica ou telefônica, com o órgão ou entidade detentora do sítio; e VIII - adotar as medidas necessárias para garantir a acessibilidade de conteúdo para pessoas com deficiência" (BRASIL, 2011, www.planalto.gov.br).

Barbarói, Santa Cruz do Sul, Edição Especial n.44, p.<137-154>, jul./dez. 2015 
disposto acima como argumento para escusar-se no enfrentamento da corrupção ${ }^{15}$. Pelo contrário, é absolutamente imprescindível a atuação estatal no controle dessa patologia social, com vistas a garantir o equilíbrio das contas públicas, assegurar a moralidade administrativa e, especialmente, proporcionar aos seus cidadãos políticas públicas que sejam condizentes com os elevados tributos arrecadados neste país.

A despeito disso, faz-se mister reconhecer que o Estado "sozinho" não possui aptidão para enfrentar eficazmente a corrupção. Primeiramente, porque, muitas vezes, os próprios gestores estatais estão envolvidos nas práticas corruptivas, tornando ilusório acreditar que o governo atuaria, de fato, em desproveito de seus interesses. Secundariamente - mas não menos importante -, em razão da inviabilidade de se combater, por uma só via, um fenômeno tão disperso e abstruso como é a corrupção.

Destarte, a fim de promover um controle verdadeiramente amplo e eficaz das patologias corruptivas, faz-se necessária a implementação de mecanismos político-sociais, fundados nos princípios da publicidade e da transparência (o que, aliás, é exigência tanto do direito internacional quanto do direito nacional) propendentes a incentivar ou, ao menos, permitir que cada cidadão brasileiro seja, mutatis mutandis, um fiscal da administração pública.

\section{Referências}

ASSIS, Machado de. Volume de contos. Rio de Janeiro: Garnier, 1884. Disponível em <www.dominiopublico.gov.br>. Acesso em: 29 jul. 2015.

BÍBLIA. Português. A Bíblia Sagrada: edição corrigida e revisada, fiel ao texto original. Tradução de João Ferreira de Almeida. Disponível em: <www.bibliaonline.com.br>. Acesso em: 28 jul. 2015.

BRASIL. Constituição (1988) Constituição da República Federativa do Brasil. Disponível em: <www.planalto.gov.br>. Acesso em: $1^{\circ}$ ago. 2015.

BRASIL. Lei Complementar $n^{\circ} 101$, de 4 de maio de 2000. Lei de Responsabilidade Fiscal. Disponível em: <www.planalto.gov.br>. Acesso em: 3 ago. 2015.

BRASIL. Lei Complementar $n^{\circ}$ 131, de 27 de maio de 2009. Lei da Transparência. Disponível em: <www.planalto.gov.br>. Acesso em: 3 ago. 2015.

BRASIL. Lei $\mathrm{n}^{\circ}$ 12.527, de 18 de novembro de 2011. Lei de Acesso à Informação. Disponível em: <www.planalto.gov.br>. Acesso em: 5 ago. 2015.

15 Argumentos do tipo "ah! A corrupção é algo natural/cultural...então é impossível combatê-la" são relativamente comuns; mas, definitivamente, não são, sob nenhum ângulo, argumentos satisfatórios. 
BRASIL. Lei $\mathrm{n}^{\circ}$ 8.429, de 2 de junho de 1992. Lei de Improbidade Administrativa. Disponível em: <www.planalto.gov.br>. Acesso em: 5 ago. 2015.

BRASIL. Portal da Transparência. Sobre o Portal. Disponível em: <www.portaldatransparencia.gov.br>. Acesso em 3 ago. 2015.

DEMÓCRITO. In: Gerd A. Bornheim (Org.). Os filósofos pré-socráticos. São Paulo: Cultrix, 1998.

GORCZEVSKI, Clovis. Cidadania ativa e virtude cívica para o combate às patologias corruptivas. In: COSTA, M. M. M. da; LEAL, M. C. H. (Org.). Direitos sociais \& políticas públicas: desafios contemporâneos. Santa Cruz do Sul: EDUNISC, 2014.

. Direitos humanos, educação e cidadania: conhecer, educar, praticar. Santa Cruz do Sul: EDUNISC, 2012.

GORCZEVSKI, C.; MARTIN, N. B. A necessária revisão do conceito de cidadania: movimentos sociais e novos protagonistas na esfera pública democrática. Santa Cruz do Sul: EDUNISC, 2011.

GUERRA, Evandro Martins. Os Controles Externo e Interno da Administração Pública e os Tribunais de Contas. Belo Horizonte: Fórum, 2003.

HERÁCLITO. In: Gerd A. Bornheim (Org.). Os filósofos pré-socráticos. São Paulo: Cultrix, 1998.

HOBBES, Thomas. Leviatã, ou matéria, forma e poder de um Estado eclesiástico e civil. São Paulo: Martin Claret, 2006.

LEAL, Rogério Gesta. A administração pública compartida no Brasil e na Itália: reflexões preliminares. Santa Cruz do Sul: EDUNISC, 2008.

LEAL, Rogério Gesta. Patologias corruptivas nas relações entre estado, administração pública e sociedade: causas, consequências e tratamentos. Santa Cruz do Sul: EDUNISC, 2013.

Como os déficits de interlocução política atingem a atuação da cidadania democrática no Brasil. Revista do Instituto de Hermenêutica Jurídica, Belo Horizonte, v. 1, n. $1,2009$.

LOUREIRO, Patrícia. A cidadania da União Europeia: mito ou realidade? In: SOUSA, M. T. C.; LOUREIRO, P. (Org.). Cidadania: novos temas, velhos desafios. Ijuí: Unijuí, 2009.

MARÇAL FILHO, Justen. Curso de direito administrativo. São Paulo: Saraiva, 2005 .

ORGANIZAÇÃO DAS NAÇÕES UNIDAS (ONU). Convenção das Nações Unidas contra a Corrupção. Mérida, 2003. Disponível em <www.planalto.gov.br> Acesso em 30 jul. 2015.

ORGANIZAÇÃO DOS ESTADOS AMERICANOS (OEA). Convenção Interamericana

Barbarói, Santa Cruz do Sul, Edição Especial n.44, p.<137-154>, jul./dez. 2015 
contra a Corrupção. 1996. Disponível em <www.planalto.gov.br> Acesso em 30 jul. 2015.

PATTIDOUG. Doug (S04E19): 'Doug's in the Money' [FULL EPISODE]. Disponível em: <www.youtube.com>. Acesso em: 26 jul. 2015

RIO GRANDE DO SUL. Constituição (1989) Constituição do Estado do Rio Grande do Sul. Disponível em: <www.al.rs.gov.br>. Acesso em: 2 ago. 2015.

ROUSSEAU, Jean-Jacques. O Contrato Social. São Paulo: Russel, 2006.

SIMÃO, Calil. Improbidade Administrativa: Teoria e Prática. Leme: J.H. Mizuno, 2011.

SÓFOCLES. Antígona. Porto Alegre: L\&PM, 2011. E-book. ISBN 978-85-254-0814-3 (recurso eletrônico).

STARLING, Heloisa Maria Murgel. Ditadura Militar. In: AVRITZER, Leonardo (Org.). Corrupção: ensaios e críticas. Belo Horizonte: UFMG, 2008.

TRANSPARENCY INTERNATIONAL. What is transperency?. Disponível em: <www.transparency.org>. Acesso em: 08 ago. 2015.

\section{Sobre os autores:}

Thiago Heitor da Fontoura Porto é Mestrando do Programa de Pós-graduação em Direito Mestrado e Doutorado da Universidade de Santa Cruz do Sul - UNISC. Bacharel em Direito pela Universidade de Santa Cruz do Sul - UNISC. Pós-graduado (lato sensu) em Direito Público pela Fundação Escola Superior do Ministério Público. Servidor Público Federal (Analista Processual do Ministério Público da União). Integrante do grupo de pesquisas "Jurisdição Constitucional aberta: uma proposta de discussão da legitimidade e dos limites da jurisdição constitucional - instrumentos teóricos e práticos", coordenado pela Professora PósDr ${ }^{\mathrm{a}}$. Mônia Clarissa Hennig Leal. Endereço Eletrônico: thfporto@ hotmail.com

Caroline Cristiane Werle é Mestranda do Programa de Pós Graduação em Direito - Mestrado e Doutorado da Universidade de Santa Cruz do Sul - UNISC, com bolsa promovida pela CAPES (Coordenação de Aperfeiçoamento de Pessoal de Nível Superior). Graduada em Direito pela Universidade de Santa Cruz do Sul - UNISC. Advogada. Integrante do grupo de pesquisas "Intersecções Jurídicas entre o Público e Privado" coordenado pelo professor PósDoutor Jorge Renato dos Reis, vinculado ao programa de Pós Graduação em Direito Mestrado e Doutorado da Universidade de Santa Cruz do Sul - UNISC. Endereço eletrônico: ccwerle@yahoo.com.br 